\title{
Evaluation of Influence Factors in Diesel Truck Pollution Control
}

\author{
Qiang Wang ${ }^{1, \mathrm{a}}$, Haiying Liu ${ }^{* 2, \mathrm{~b}}$, Jiaxin Wang ${ }^{3, \mathrm{c}}$, Xin Liu and Jiaoyu He $\mathrm{He}^{4, \mathrm{~d}}$ \\ ${ }^{1}$ Affilication: Department of Mechanical and Traffic Engineering, Ordos Institute of Technology, Ordos, China \\ ${ }^{2}$ Affilication: Department of Management, Ordos Institute of Technology, Ordos, China \\ ${ }^{3}$ Affilication: School of Finance and taxation, Inner Mongolia University of Finance and Economics, Hohhot, China \\ ${ }^{4}$ Affilication: School of Finance and taxation, Inner Mongolia University of Finance and Economics, Hohhot, China
}

\begin{abstract}
Diesel truck pollution emissions are major air polluting sources. Pollution control of diesel trucks is one of the important measures to improve air management. In order to study the influence factors in diesel trucks pollution control, an evaluation system consisting of one target layer, three criterion layers and 15 indicator layers was constructed. Through the comprehensive evaluation software Super Decision, the consistency test is passed, and the weight values of each indicator are obtained. Results show that the most important factor that affects the degree of diesel truck pollution is the number of law enforcement officers, with a weight of 0.24 . The sum of weights of number of law enforcement officers, popularizing rate of environmental knowledge, blacklist rate, diesel trucks inspection rate, pollution control device configuration rate, correct use rate of pollution control devices, diesel truck emission standards is up to 0.84 , which indicates that the seven influence factors determine diesel truck pollution control. The conclusions provide references in formulating measures to diesel truck.
\end{abstract}

\section{Introduction}

With the rapid development of China's economy, in a certain period of time, the state does not pay much attention to air pollution control, which in turn leads to serious air pollution. Diesel truck pollution emissions are major air polluting sources. Although some measures have been taken in some places, the effects are often not particularly significant due to the spread of pollution emissions. At the same time, China is a big manufacturing country, where industrial development requires diesel trucks for a large proportion of logistics. All of these conditions make China's diesel truck pollution control complex.

Although mature research on biodiesel, diesel truck pollution analysis and control technology control has been conducted at home and abroad, most studies are confined to the narrow sense of diesel truck pollution analysis and control technology. In the research of diesel truck pollution control, it is rare find consider the factors of diesel truck drivers and government management to study diesel truck pollution control. Therefore, it is of great practical significance and application value to study the impact of diesel truck pollution control.

\section{Materials And Methods}

\subsection{Construction of index system:}

To construct a diesel truck pollution control index system, it is necessary to comprehensively consider diesel truck factors, environmental factors, government management factors and diesel truck driver factors. In summary, in order to solve the problem of diesel trucks pollution control, a three-layer index system with target layer, criterion layer and index layer is constructed. The diesel trucks pollution control indicator system includes one target layer, four criterion layers and fifteen indicator layers are shown in Table 1.

Table1. Evaluation index system of diesel truck pollution influence factors

\begin{tabular}{|c|c|c|c|}
\hline Target Layer & Criterion Layer & Index Level & Index Interpretation \\
\hline \multirow{5}{*}{$\begin{array}{c}\text { D: } \\
\text { Diesel truck } \\
\text { pollution } \\
\text { control } \\
\text { influence } \\
\text { degree }\end{array}$} & \multirow[t]{5}{*}{$\begin{array}{c}\text { V1: } \\
\text { Vehicle factors }\end{array}$} & E1: Diesel truck ownership (trucks) & $\begin{array}{l}\text { The sum of the number of diesel trucks in a country or } \\
\text { region. }\end{array}$ \\
\hline & & $\begin{array}{l}\text { E2: Annual mileage of diesel trucks } \\
\text { (Km/years) }\end{array}$ & $\begin{array}{l}\text { The sum of the distance traveled by a diesel truck in one } \\
\text { year. }\end{array}$ \\
\hline & & $\begin{array}{l}\text { E3: Pollution control device } \\
\text { configuration rate }(\%)\end{array}$ & $\begin{array}{l}\text { Ratio of diesel truck with pollution control device to diesel } \\
\text { truck. }\end{array}$ \\
\hline & & $\begin{array}{l}\text { E4: On-board diagnostics proper } \\
\text { use ratio }(\%)\end{array}$ & $\begin{array}{l}\text { Ratio of diesel truck with on-board diagnostics proper use } \\
\text { to diesel truck. }\end{array}$ \\
\hline & & $\begin{array}{l}\text { E5: New diesel trucks' pollutant } \\
\text { discharge compliance rate }(\%)\end{array}$ & $\begin{array}{l}\text { Ratio of new diesel trucks' pollutant discharge compliance } \\
\text { to new diesel truck. }\end{array}$ \\
\hline
\end{tabular}

aEmail: edwangqiang@126.com

bEmail: lhy_liuhaiying@163.com, Correspondence: lhy_liuhaiying@163.com,Tel.: +86-186-8623-7979/0477-8591194

'Email: 422612339@qq.com, ${ }^{\mathrm{d}}$ Email: 3092076139@qq.com and 3544378722@qq.com 


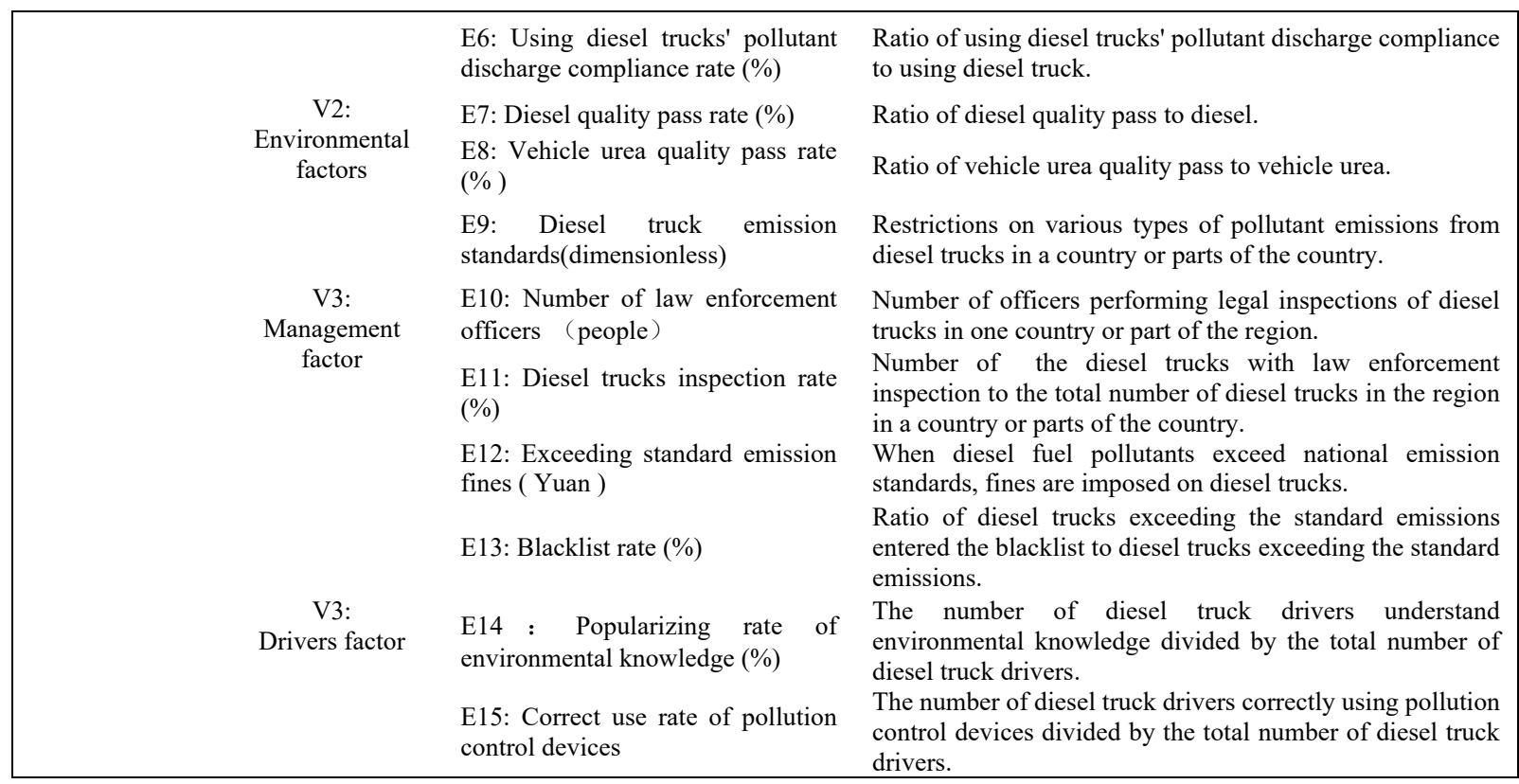

\subsection{Evaluation method:}

Analytic hierarchy process (AHP), a comprehensive evaluation method, can achieve qualitative and quantitative analysis.

Specific steps are as follows:

(1) Identifying research target: diesel truck pollution control influence degree.

(2) Building a hierarchical model: the hierarchical model of the 4 criteria layers and 15 indexes of the diesel truck pollution influence degree is determined, and the evaluation index system of the diesel truck pollution influence factors is established, as shown in Table 1.

(3) Building a judgment matrix: Compare the relative importance of each criterion at each level and give a judgment. This article uses the 1-9 scale method recommended by Saaty.

(4) Single impact weight sorting: For each criterion, the evaluation value of the influencing factors of diesel truck pollution control is given, which constitutes a judgment matrix and finds its corresponding weight. The method is to calculate that the judgment matrix A satisfies the equation:

$$
A W=\lambda_{\max }
$$

Where $\mathrm{W}$ is defined as a eigenvector, and also a single sort weight; $\lambda_{\max }$ is defined as the largest eigenvalues.

(5) Total impact weight sorting: Calculate the combined weight value of each influence factor.

A consistency check is required when single impact weight sorting and total impact weight sorting to ensure that it is logically reasonable. The steps for the consistency check are as follows:

\subsubsection{Computational consistency indicator:}

$$
C I=\frac{\lambda_{\max }}{n-1}
$$

Where $C I$ is defined as consistency indicator; $n$ is defined as number of evaluation indicators.

\subsubsection{Query the average random consistency indicator value:}

$\mathrm{RI}$ is defined as average random consistency indicator. By querying the average random consistency indicator value table, the corresponding average random consistency index RI value can be determined when different $\mathrm{n}$ values are determined, as shown in Table 2.

\begin{tabular}{|c|c|c|c|c|c|c|c|c|c|c|c|c|c|}
\hline $\mathrm{n}$ & 1 & 2 & 3 & 4 & 5 & 6 & 7 & 8 & 9 & 10 & 11 & 12 & 13 \\
\hline RI & 0 & 0 & 0.58 & 0.9 & 1.12 & 1.24 & 1.32 & 1.41 & 1.45 & 1.49 & 1.52 & 1.54 & 1.56 \\
\hline
\end{tabular}

Table2. The average random consistency indicator value

\subsubsection{Calculate the consistency ratio:}

$$
C R=\frac{C I}{R I}
$$

When $\mathrm{CR}<0.1$, it is considered that the consistency of the judgment matrix is acceptable. When $\mathrm{CR} \geq 0.1$, the judgment matrix does not meet the consistency requirement, the judgment matrix needs to be re-corrected.

\section{Results And Analysis}

In the study of the influence factors in diesel trucks pollution control, the analysis process is divided into three steps: first, six experts focus on the discussion, according 
to the 1-9 method, the three criterion layers are compared in pairs, and the weights of the three criteria in the criterion layer are determined; second, the six experts focus on the discussion, according to the 1-9 method, 15 indicators are evaluated to determine the individual weights; third, determine the weight of the comprehensive evaluation, as shown in Tables 3-7.

Table3. Scale comparison matrix D-V.

\begin{tabular}{|ccccc|}
\hline $\mathrm{D}$ & $\mathrm{V} 1$ & $\mathrm{~V} 2$ & $\mathrm{~V} 3$ & $\mathrm{~V} 4$ \\
\hline $\mathrm{V} 1$ & 1 & 3 & 0.25 & 0.33 \\
$\mathrm{~V} 2$ & 0.33 & 1 & 0.33 & 0.5 \\
$\mathrm{~V} 3$ & 4 & 3 & 1 & 0.33 \\
$\mathrm{~V} 4$ & 3 & 2 & 3 & 1 \\
\hline
\end{tabular}

Table4. Scale comparison matrix V1 -E.

\begin{tabular}{|ccccccc|}
\hline V1 & E1 & E2 & E3 & E4 & E5 & E6 \\
\hline E1 & 1 & 0.2 & 0.14 & 0.33 & 0.5 & 0.2 \\
E2 & 5 & 1 & 7 & 0.25 & 0.5 & 0.25 \\
E3 & 7 & 7 & 1 & 4 & 5 & 4 \\
E4 & 3 & 4 & 0.25 & 1 & 0.25 & 0.25 \\
E5 & 2 & 2 & 0.2 & 4 & 1 & 0.5 \\
E6 & 5 & 4 & 0.25 & 4 & 2 & 1 \\
\hline
\end{tabular}

Table5. Scale comparison matrix V2 -E.

\begin{tabular}{|cccc|}
\hline V2 & E7 & E8 & E9 \\
\hline E7 & 1 & 0.14 & 0.2 \\
E8 & 7 & 1 & 0.33 \\
E9 & 5 & 3 & 1 \\
\hline
\end{tabular}

Table6. Scale comparison matrix V3 -E.

\begin{tabular}{|ccccc|}
\hline V3 & E10 & E11 & E12 & E13 \\
\hline E10 & 1 & 5 & 3 & 2 \\
E11 & 0.2 & 1 & 5 & 0.5 \\
E12 & 0.33 & 0.2 & 1 & 0.2 \\
E13 & 0.5 & 2 & 5 & 1 \\
\hline
\end{tabular}

Table7. Scale comparison matrix V4 -E.

\begin{tabular}{|ccc|}
\hline V4 & E14 & E15 \\
\hline E14 & 1 & 3 \\
E15 & 0.33 & 1 \\
\hline
\end{tabular}

According to the judgment of six experts on influence factors in diesel trucks pollution control, the judgment matrix is constructed, and the consistency judgment is made through the decision software Super Decision. When $\mathrm{CR}<0.1$, which indicates that the expert judges the consistency and does not need to make a new judgment. The calculation results are shown in Table 8.

Table8. Calculation results of weight of each layer index to target layer

\begin{tabular}{|cccccc|}
\hline Indicators & $\mathrm{V} 1$ & $\mathrm{~V} 2$ & $\mathrm{~V} 3$ & $\mathrm{~V} 4$ & $\begin{array}{c}\text { Weight } \\
\text { value }\end{array}$ \\
\hline & 0.15 & 0.10 & 0.50 & 0.25 & \\
\hline E1 & 0.04 & & & & 0.01 \\
E2 & 0.07 & & & & 0.01 \\
E3 & 0.45 & & & & 0.07 \\
E4 & 0.10 & & & & 0.02 \\
E5 & 0.14 & & & & 0.02 \\
E6 & 0.21 & & & & 0.03 \\
\hline
\end{tabular}

\begin{tabular}{|ccccc|}
\hline E7 & 0.07 & & & 0.01 \\
E8 & 0.32 & & & 0.03 \\
E9 & 0.60 & & & 0.06 \\
E10 & & 0.48 & & 0.24 \\
E11 & & 0.17 & & 0.09 \\
E12 & & 0.07 & & 0.04 \\
E13 & & 0.28 & & 0.14 \\
E14 & & & 0.75 & 0.19 \\
E15 & & & 0.25 & 0.06 \\
\hline
\end{tabular}

From the above table, it is clear that:

The most important factor that affects the degree of diesel truck pollution control is number of law enforcement officers. The weights of the indexes E10, $\mathrm{E} 14, \mathrm{E} 13, \mathrm{E} 11, \mathrm{E} 3, \mathrm{E} 15$, and $\mathrm{E} 9$ are 84\%, which indicate that the diesel truck pollution control is determined by E10, E14, E13, E11, E3, E15 and E9.

\section{Conclusion}

Based on the analysis of the influence factors in diesel truck pollution control, an evaluation index system of the influence factors in diesel truck pollution control was established. The weight of each index is sorted, and two main conclusions are drawn. First, number of law enforcement officers is the primary factor that affects diesel truck pollution control. Second, number of law enforcement officers, blacklist rate pollution control device configuration rate, diesel trucks inspection rate, diesel truck emission standards, using diesel trucks' pollutant discharge compliance rate determines diesel truck pollution control.

In this study, there are still some shortcomings, for example the use of analytic hierarchy process has certain subjectivity, which relies mainly on the subjective judgment of experts. In the future, this research can be improved from the following three aspects. First, when constructing evaluation indicators, consider more influencing factors, such as government subsidies, road factors; secondly, conduct empirical research on influencing factors, and verify the validity of the model by conducting surveys on typical areas. Finally, consider more complex interactions between different metrics, such as building a network analytic model.

\section{Acknowledgement}

This work was supported by Research Program of Science and Technology at Universities of Inner Mongolia Autonomous Region(NJSY19262); Natural Science Foundation of Inner Mongolia Autonomous Region of China(2019MS07005,2019MS07006); "Young Talents in Science and Technology" in Higher Education Institutions in Inner Mongolia Autonomous Region of China(NJYT20-A19); Innovative talent team project for ecological restoration and high-quality development of cultural tourism industry in Ordos; Talent Development Fund Project in Inner Mongolia Autonomous Region of 
China([2019]114) ; Inner Mongolia Social Science

Foundation Project (20B64).

\section{References}

1. Zhang, M., Li, H.2018. New evolutionary game model of the regional governance of haze pollution in China. Applied Mathematical Modelling, 63, 577590.

2. Xie, X.Y., Wang, Y.H. 2018. Evaluating the Efficacy of Government Spending on Air Pollution Control: A Case Study from Beijing. International journal of environmental research and public health, 16(1).

3. Li, J.R., Yu, S.Q Dynamic analysis for GovernancePollution model with education promoting control. Soft Computing,22(16): 5311-5321

4. Saaty, T.L. 1977. A scaling method for priorities in hierarchical structures. Journal of Mathematical Psychology, 15(3): 234- 281.

5. Jovanović, B. Filipović, J., Bakić, V. 2015. Prioritization of manufacturing sectors in Serbia for energy management improvement - AHP method, Energy Conversion and Management, 98:225-235.

6. Hatefi, S.M. Tamošaitienė, J. 2018. Construction Projects Assessment Based on the Sustainable Development Criteria by an Integrated Fuzzy AHP and Improved GRA Model. Sustainability, 10(4), 991.

7. Guo, X. J. 2018. Evaluation of Influence Factors in Virtual Water Flow, Nature Environment and Pollution Technology,17(4):1161-1165.

8. Li ,X., Li .J.,Sui,H.,et al. Evaluation and determination of soil remediation schemes using a modified AHP model and its application in a contaminated coking plant. Journal of hazardous materials, 353:300-311 